\title{
Methylated Cysteine Dioxygenase-1 Gene Promoter in the Serum Is a Potential Biomarker for Hepatitis B Virus-Related Hepatocellular Carcinoma
}

\author{
Yang Yang, ${ }^{1,2}$ Yu-Chen Fan, ${ }^{1,2}$ Shuai Gao, ${ }^{1}$ Cheng-Yun Dou, ${ }^{1}$ Jian-Jun Zhang, \\ Feng-Kai Sun ${ }^{1}$ and Kai Wang ${ }^{1,2}$ \\ ${ }^{1}$ Department of Hepatology, Qilu Hospital of Shandong University, Jinan, P.R. China \\ ${ }^{2}$ Institute of Hepatology, Shandong University, Jinan, P.R. China
}

\begin{abstract}
Hepatocellular carcinoma $(\mathrm{HCC})$ is the third leading cause of cancer-related mortality worldwide. Epigenetic analysis has attracted increasing attention in the molecular diagnosis of HCC. Cysteine dioxygenase 1 (CDO1) is a key enzyme in the taurine biosynthetic pathway and converts cysteine to cysteine sulfinate. The CDO1 gene is a tumor suppressor gene and is usually silenced by the methylation of its promoter in carcinogenesis. In this study, we evaluated whether the methylation status of CDO1 gene promoter is of diagnostic value for hepatitis B virus (HBV)-related HCC. The CDO1 promoter methylation status was determined in serum samples using methylation-specific polymerase chain reaction (MSP) in a cohort of 123 patients with HBV-related HCC, 28 with liver cirrhosis (LC), 29 with chronic hepatitis B (CHB) and 20 healthy controls. The frequency of the CDO1 promoter methylation in HBV-related HCC $(42.3 \%)$ was significantly higher than that in LC (14.3\%), CHB $(6.9 \%)$ and healthy controls $(0 \%)(P=0.006 ; P<$ $0.0001 ; P<0.0001$; respectively). Furthermore, in HCC patients, the frequency of $C D O 1$ promoter methylation was higher in advanced stages (III-IV) $(53 \%)$ than the early stages (I-II) $(20 \%)(P=0.001)$. Evaluation of the CDO1 promoter methylation status in serum, in combination with AFP (> $20 \mathrm{ng} / \mathrm{ml})$, significantly improved the diagnostic value, with sensitivity and specificity of $82.9 \%$ and $75.4 \%$, respectively in distinguishing $\mathrm{HCC}$ from $\mathrm{LC}$ and $\mathrm{CHB}$. In conclusion, methylation status of serum CDO1 gene promoter may be helpful in the diagnosis of $\mathrm{HCC}$ and the estimation of the HCC stages.
\end{abstract}

Keywords: $\alpha$-fetoprotein; cysteine dioxygenase 1; hepatitis B virus; hepatocellular carcinoma; methylation Tohoku J. Exp. Med., 2014 March, 232 (3), 187-194. (C) 2014 Tohoku University Medical Press

\section{Introduction}

Hepatocellular carcinoma (HCC) is the sixth most common malignant disease and the third leading cause of cancer-related mortality worldwide (Venook et al. 2010). Molecular mechanisms for the development of HCC are extremely complicated. DNA methylation pattern is one of the most frequently recognized events in carcinogenesis (Fukushige and Horii 2013). Methylation occurs in the carbon five of cytosine within the dinucleotide cytosine-phosphate-guanine $(\mathrm{CpG})$ by DNA methyltransferase (DNMT). CpGs that undergo methylation could be found either in singular situation or in clusters so-called $\mathrm{CpG}$ islands (Robertson 2005). Aberrant DNA methylation within CpG islands near the transcriptional start sites of genes usually lead to the silence of tumor suppressor genes, such as tissue inhibitor of metalloproteinase 3 (TIMP3) (Guan et al. 2013), suppressors of cytokine signalling-1 (SOCS-1) (Tischoff et al. 2007), and runt-related transcription factor 3
(RUNX3) (Zheng et al. 2013).

Circulating cell-free DNA (cfDNA) is a type of extracellular DNA, which is derived from both apoptotic or necrotic cells and cancer cells and is detectable in blood (Jahr et al. 2001); it may contain various alterations, such as changes in DNA strand integrity, frequency of mutation, and methylation of genes in cancer patients (Jung et al. 2010). Many tumor suppressor genes are found to have aberrant methylation in cfDNA among patients with HCC, such as $p 16$, ras-association domain family-1 (RASSF1) (Zhang et al. 2007; Shivapurkar and Gazdar 2010), glutathione-S-transferase P1 (GSTP1) (Wang et al. 2006), and adenomatous polyposis coli (APC) (Nishida et al. 2013). The aberrant methylation in HCC patients could potentially serve as a minimally noninvasive biomarker for early detection of the tumor.

Cysteine dioxygenase 1 (CDO1) is a key enzyme in the taurine biosynthetic pathway and is responsible for the conversion of cysteine to cysteine sulfinate (Satsu et al.

Received November 29, 2013; revised and accepted February 18, 2014. Published online March 18, 2014; doi: 10.1620/tjem.232.187.

Correspondence: Kai Wang, M.D., Ph.D., Department of Hepatology, Qilu Hospital of Shandong University and Institute of Hepatology,

Shandong University, Wenhuaxi Road 107 \#, Jinan 250012, P.R. China.

e-mail: wangdoc876@126.com; wangdoc2010@163.com 
2003). CDO1 is expressed highly in the liver and placenta, and at lower levels in the heart, brain and pancreas (Tsuboyama-Kasaoka et al. 1999). The frequency of the CDO1 promoter methylation and the down regulation of CDO1 expression have been studied in various cancers including breast (Dietrich et al. 2010), lung (Kwon et al. 2012), colon, esophagus, and stomach (Brait et al. 2012). In this study, we investigated the relationship between the methylation status of the CDO1 promoter in serum and $\mathrm{HCC}$ in a cohort comprising of patients with hepatitis B virus (HBV)-related HCC, liver cirrhosis (LC), or chronic hepatitis B (CHB) and healthy controls. We have found that the methylation status of $C D O 1$ gene in serum may be of value in both diagnosis of HBV-related HCC and estimation for the stages of HCC.

\section{Materials and Methods}

\section{Patients}

A total of 200 subjects visiting the Qilu Hospital of Shandong University from July 2011 to December 2012 were consecutively enrolled, including 123 patients with HBV-related HCC, 28 patients with LC, 29 patients with $\mathrm{CHB}$ and 20 healthy controls. The flowchart of all the subjects enrolled was shown in Fig. 1. Patients with HCC were diagnosed based on the guidelines of the American Association for the Study of Liver Disease (Bruix et al. 2005). HCC was defined on the basis of at least two dynamic imaging modalities including angiography, computed tomography (CT), and magnetic resonance imaging (MRI), or by tumor biopsy. For the purpose of this study, we classified tumors with Tumor Node Metastasis (TNM) stage I-II as early stage of HCC and TNM stage III-IV as advanced stage of HCC. All patients with CHB or LC were confirmed not having HCC using ultrasonography or CT; no patients had newly devel-

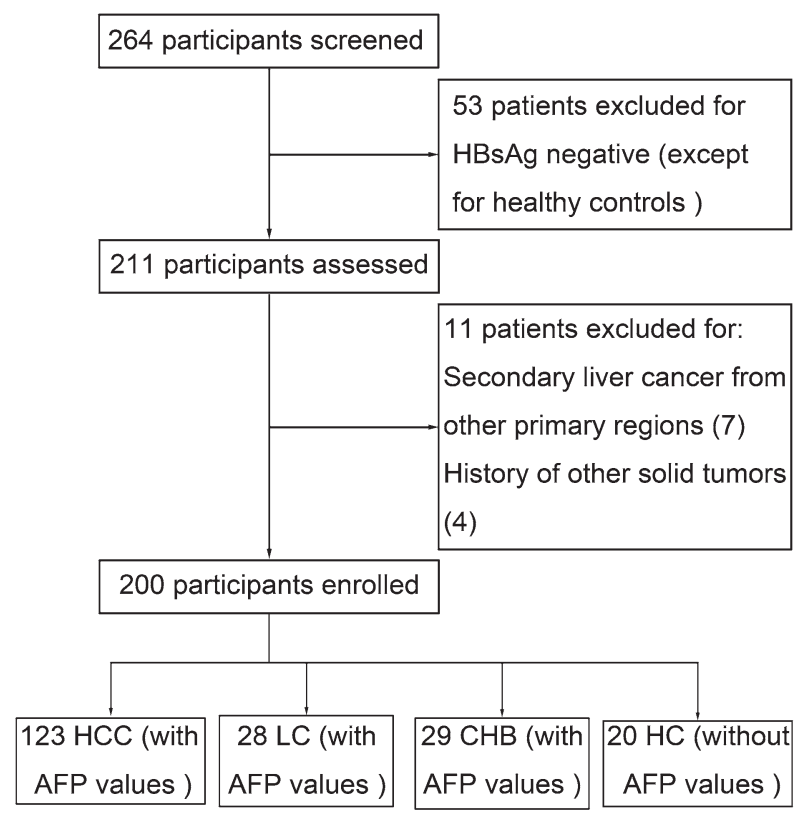

Fig. 1. Flowchart for the selection process of the subjects. HBsAg, hepatitis B virus surface antigen. HCC, hepatocellular carcinoma. AFP, a-fetoprotein. CHB, chronic hepatitis B. LC, liver cirrhosis. oped HCC for at least 3 months before enrolment. The healthy controls were recruited from the eligible blood donors, who had no history of liver disease, viral hepatitis, and malignant disease.

Clinical information was collected from the medical records of the patients. Hepatitis B e Antigen ( $\mathrm{HBeAg}$ ) in the serum of the patients and healthy controls were quantitatively assayed using electro-chemiluminescence on an E170 modular immunoassay analyzer (Roche Diagnostics, Mannheim Germany). HBeAg > 0.5 PEIU/ml was recognized negative. Serum $\alpha$-fetoprotein (AFP) levels were measured by eletro-chemiluminescence immunoassay using COBAS e 601 automatic analyzer (Roche Diagnostics, Mannheim, Germany). The biopsies were paraffin embedded with haematoxylin-eosin staining. The histological grade of tumor differentiation was assigned based on the Edmondson and Steiner's classification system (Edmondson and Steiner 1954). Tumor size was measured as the largest diameter of the tumor. Multinodular tumors were defined as tumors with more than two nodules (including satellite nodules surrounding a larger main tumor). In our study, the presence of portal vein $(\mathrm{PV})$ tumor thrombosis or hepatic vein $(\mathrm{HV})$ tumor thrombosis was recognized as vascular invasion. This study was approved by the Ethics Committee of Shandong University Qilu Hospital and written informed consent was obtained from all subjects.

\section{DNA extraction and sodium bisulfite modification}

Genomic DNA was extracted from serum by using a QIAamp DNA Blood Mini Kit (Qiagen GmbH, Hilden, Germany) according to the manufacturer's instructions. In order to obtain enough quantity of DNA, $400 \mu \mathrm{l}$ serum was used as each sample. $20 \mu \mathrm{l}$ extracted DNA was modified with sodium bisulfite by using the EZ DNA Methylation-Gold Kit TM (Zymo Research Corp, Orange, CA, USA) according to the manufacturer's instructions. Bisulfite treatment can be used for detecting 5-methylcytosine in DNA by converting all cytosine residues to uracil, while those methylated cytosine are resistant to this modification and remain as cytosine (Fraga and Esteller 2002).

\section{Methylation-specific PCR}

Methylation-specific PCR (MSP) was used to detect CDO1 promoter methylation status. Bisulphite modified DNA samples were PCR-amplified using either an unmethylation-specific (CDOIU) or methylation-specific (CDOIM) primer pairs described before (Fig. 2) (Andresen et al. 2012). The methylation primer sense was 5'-TTGGGACGTCGGAGATAAC-3' and antisense, 5'-GACCCT CGAAAAAAAA ACGA-3'. The unmethylation primer sense was 5'-TTTTTGGGATGTTGGAGATAAT-3' and antisense, 5'-AACCCT CAAAAAAAA AACAAAAC-3'. PCR was performed in a volume of $25 \mu$ l containing $10.5 \mu \mathrm{l} 1 \times$ PCR buffer, $12.5 \mu \mathrm{l}$ Taq polymerase (Zymo Research Corp, CA, USA), $0.5 \mu \mathrm{l}(20 \mu \mathrm{M})$ of each primer and $1 \mu \mathrm{l}$ bisufite-treated DNA. The mixture was incubated for 10 minutes at $95^{\circ} \mathrm{C}$, followed by 45 cycles of denaturing at $95^{\circ} \mathrm{C}$ for 30 seconds, annealing at $53^{\circ} \mathrm{C}$ for 30 seconds, extension at $72^{\circ} \mathrm{C}$ for 40 seconds and a final extension at $72^{\circ} \mathrm{C}$ for 10 minutes. Water without DNA was used as a negative control. PCR products were then electrophoresed on a $2 \%$ agarose gel, stained with gelred (Biotium, California, USA), and visualized under UV illumination.

\section{Statistical analysis}

All data were analyzed using SPSS 16.0 statistics software (SPSS, Chicago, IL). Serum CDO1 promoter methylation status in 


\section{CDO1 GENE}

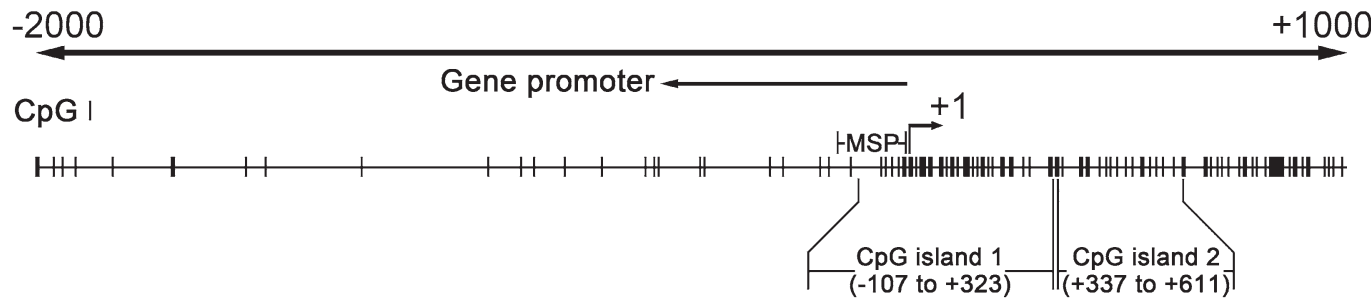

Fig. 2. Schematic representation of cysteine dioxygenase 1 (CDO1) gene. According to the study of Andresen et al., we retested the validity of the primer using Methyl Primer Express Software v1.0. CpG island prediction criteria used: Island size $>100, \mathrm{GC}$ Percent $>50.0, \mathrm{Obs} / \operatorname{Exp}>0.60$. The transcription start site is indicated by a curved arrow. The location of $\mathrm{CpG}$ islands, promoter regions $(\leftarrow)$, and MSP-amplified regions $(\mathrm{M},-153$ to -8 ; $\mathrm{U},-156$ to -8$)$ are indicated.
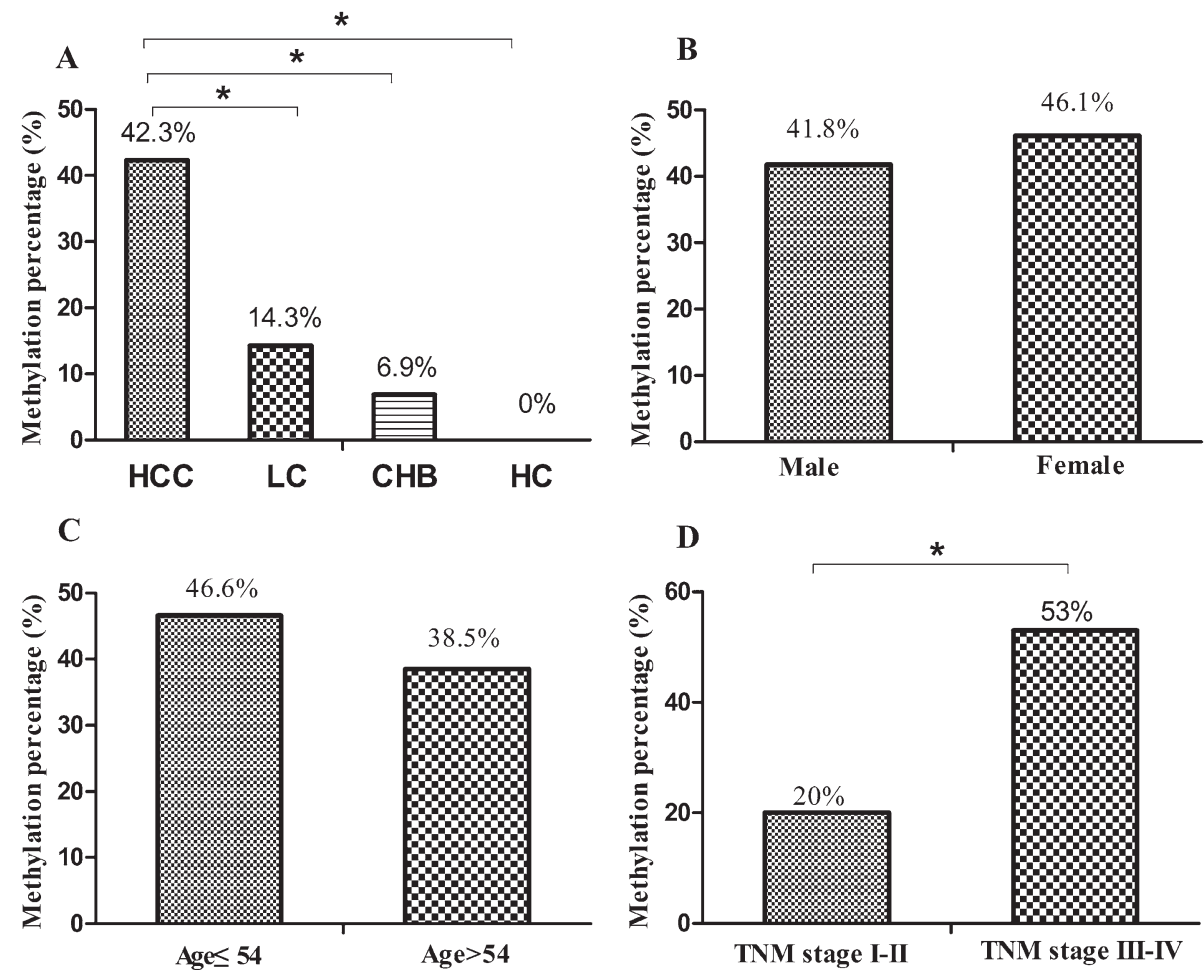

Fig. 3. The comparison of methylation status in different diseases, sex, age, and TNM stages. A: The frequency of methylation of CDO1 promoter in hepatocellular carcinoma, liver cirrhosis (LC), chronic hepatitis B (CHB) groups and healthy controls $\left({ }^{*} P<0.05\right)$. B: No significant difference in methylation frequency was shown between male and female groups $(P=0.765)$ in HCC patients. C: No significant correlation was shown between methylation frequency and age $(P=$ $0.365)$ in HCC patients. D: Increased methylation frequency of $C D O 1$ promoter in patients with advanced stages III-IV was observed compared with those with early stages I-II. $(P=0.001) . * P<0.05$.

patients with HBV-related $\mathrm{HCC}$, liver cirrhosis, $\mathrm{CHB}$, and healthy controls were compared using chi-square test and Fisher's exact test. The correlation between CDO1 methylation status of patients with HBV-related HCC and their clinical characteristics were evaluated using chi-square test. Univariate logistic regression analysis was used to estimate odds ratios (OR) and $95 \%$ confidence intervals (CIs) for each parameter including tumors size $>5 \mathrm{~cm}$, multi-nodular tumors, portal or hepatic vein invasion and advanced stages III-IV. $P$ value $<0.05$ was considered statistically significant.

\section{Results}

CDO1 promoter methylation in HBV-related HCC, LC and $\mathrm{CHB}$

The frequencies of methylated $C D O 1$ promoter in serum were $42.3 \%$ in patients with HBV-related HCC (52/123), $14.3 \%$ in patients with LC (4/28), 6.9\% in patients with CHB (2/29), and $0 \%$ in healthy controls $(0 / 20)$ (Fig. $3 \mathrm{~A})$. Thus, the frequency of methylated CDO1 promoter was significantly higher in HCC patients than any other groups $(P=0.006 ; P<0.0001$; and $P<0.0001$, respectively). In contrast, the methylation status of serum $C D O 1$ 


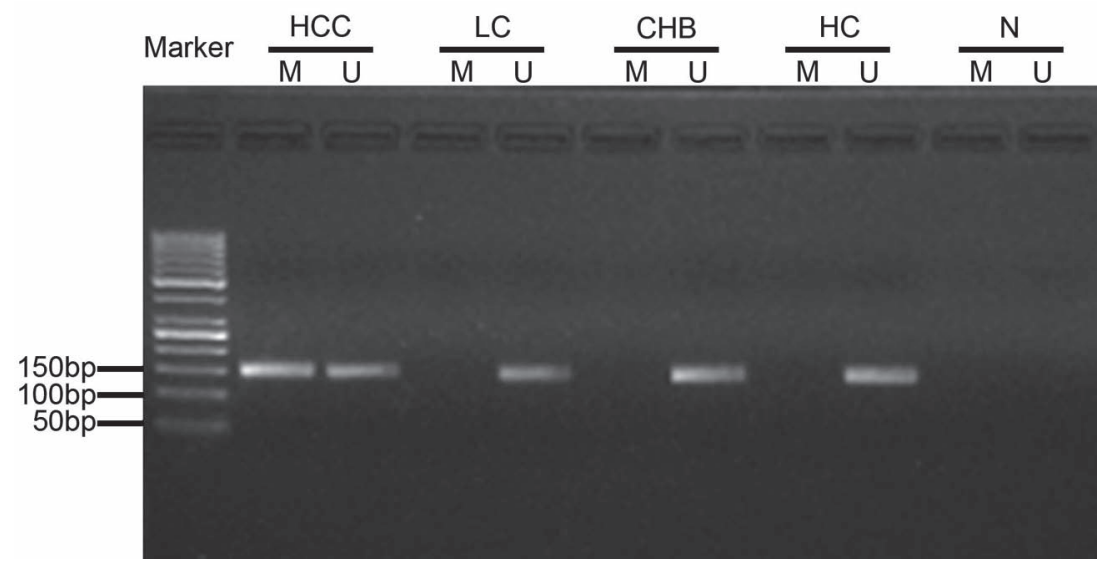

Fig. 4. Typical methylation-specific PCR (MSP) analysis results of $C D O 1$ gene promoter. M: represents methylation-specific state of $\mathrm{CpG}$ island on $\mathrm{CDO1}$ gene promoter (145 bp M lanes); $\mathrm{U}$ : represents unmethylation-specific state (148 bp U lanes); N: represents negative control.

Table 1. The correlation of $C D O 1$ promoter methylation and the basic clinical characters of HCC.

\begin{tabular}{|c|c|c|c|c|}
\hline \multirow{2}{*}{ Characteristics } & \multicolumn{2}{|c|}{ CDO1 promoter methylation status } & \multirow{2}{*}{$X_{2}$} & \multirow{2}{*}{$P$} \\
\hline & Methylated & Unmethylated & & \\
\hline Total number & 52 & 71 & & \\
\hline Gender & & & 0.09 & 0.765 \\
\hline Male & 46 & 64 & & \\
\hline Female & 6 & 7 & & \\
\hline Age (years) & & & 0.822 & 0.365 \\
\hline$\leq 54$ & 27 & 31 & & \\
\hline$>54$ & 25 & 40 & & \\
\hline $\mathrm{HBeAg}$ & & & 0.945 & 0.331 \\
\hline Positive & 10 & 19 & & \\
\hline Negative & 42 & 52 & & \\
\hline AFP $20 \mathrm{ng} / \mathrm{mL}$ & & & 2.805 & 0.094 \\
\hline$\leq 20$ & 23 & 21 & & \\
\hline$>20$ & 29 & 50 & & \\
\hline Liver cirrhosis & & & 1.136 & 0.287 \\
\hline With & 40 & 60 & & \\
\hline Without & 12 & 11 & & \\
\hline TNM stage & & & 12.054 & 0.001 \\
\hline I-II & 8 & 32 & & \\
\hline III-IV & 44 & 39 & & \\
\hline Histological differentiation & & & 2.146 & 0.143 \\
\hline Well/moderate & 18 & 14 & & \\
\hline Poor & 5 & 10 & & \\
\hline Unknown & 29 & 47 & & \\
\hline
\end{tabular}

promoter in LC or CHB patients was similar to that in healthy controls $(P=0.130$ and $P=0.507$, respectively). Fig. 4 represents a typical result of $C D O 1$ promoter methylation by MSP.
Correlation of CDO1 promoter methylation and clinical characteristics of $H B V$-related $H C C$

The correlation of the $C D O 1$ promoter methylation with the clinical characteristics of HCC is shown (Table 1). There was no significant difference in the frequency of the 
Table 2. The univariate logistic regression of the $C D O 1$ promoter methylation with the characteristics of HCC.

\begin{tabular}{lcccc}
\hline & $\begin{array}{c}\text { Tumor size } \\
>5 \mathrm{~cm}\end{array}$ & $\begin{array}{c}\text { Multinodular } \\
\text { tumors }\end{array}$ & $\begin{array}{c}\text { PV or HV } \\
\text { invasion }\end{array}$ & $\begin{array}{c}\text { TNM stage } \\
\text { III-IV }\end{array}$ \\
\hline$P$ & 0.001 & 0.004 & 0.000 & 0.001 \\
OR & 3.834 & 3.183 & 4.04 & 4.513 \\
$95 \% \mathrm{CI}$ & $1.702-8.635$ & $1.461-6.932$ & $1.883-8.669$ & $1.86-10.952$ \\
\hline
\end{tabular}

Table 3. Diagnostic value of AFP and CDO1 promoter methylation status in discriminating HBV-related HCC from LC and CHB.

\begin{tabular}{|c|c|c|c|c|c|c|c|c|c|}
\hline \multirow{2}{*}{$\begin{array}{l}\text { AFP cutoff level } \\
(\mathrm{ng} / \mathrm{mL})\end{array}$} & \multicolumn{3}{|c|}{20} & \multicolumn{3}{|c|}{200} & \multicolumn{3}{|c|}{400} \\
\hline & SE $(\%)$ & SP $(\%)$ & $\mathrm{Y}$ & SE (\%) & $\mathrm{SP}(\%)$ & $\mathrm{Y}$ & SE (\%) & SP $(\%)$ & $\mathrm{Y}$ \\
\hline \multicolumn{10}{|l|}{$\mathrm{HCC}$ vs. $\mathrm{LC}+\mathrm{CHB}$} \\
\hline CDO1 only & 42.3 & 89.5 & 31.8 & 42.3 & 89.5 & 31.8 & 42.3 & 89.5 & 31.8 \\
\hline AFP only & 64.2 & 84.2 & 48.4 & 32.5 & 98.2 & 30.7 & 22.8 & 98.2 & 21 \\
\hline$C D O 1+\mathrm{AFP}$ & 82.9 & 75.4 & 58.3 & 64.2 & 87.7 & 51.9 & 57.7 & 87.7 & 45.4 \\
\hline \multicolumn{10}{|l|}{ HCC vs. LC } \\
\hline CDO1 only & 42.3 & 85.7 & 28 & 42.3 & 85.7 & 28 & 42.3 & 85.7 & 28 \\
\hline AFP only & 64.2 & 67.9 & 32.1 & 32.5 & 96.4 & 28.9 & 22.8 & 96.4 & 19.2 \\
\hline$C D O 1+\mathrm{AFP}$ & 82.9 & 57.1 & 40 & 64.2 & 82.1 & 46.3 & 57.7 & 82.1 & 39.8 \\
\hline
\end{tabular}

CDO1, methylated $C D O 1$ promoter.

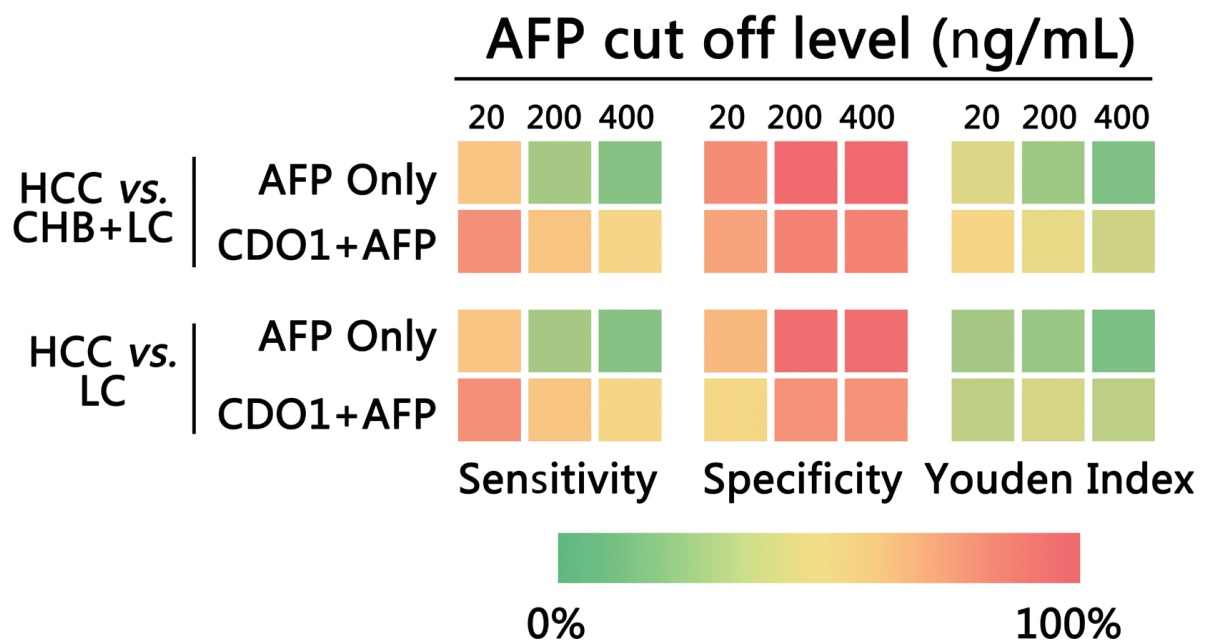

Fig. 5. The color gradation chart of sensitivity, specificity and Youden index. The sensitivity, specificity and Youden index is compared at different AFP cutoff levels of in HCC vs. LC, and HCC vs. LC + CHB. In all cases the combined biomarker showed higher sensitivity and Y-index than AFP alone.

CDO1 promoter methylation between male and female $(P=$ 0.765 ) (Fig. 3B) and between young (age $\leq 54$ years) and old people (age $>54$ years) $(P=0.365)$ (Fig. 3C). However, significantly higher frequency of the $C D O 1$ promoter methylation was observed in patients with advanced stages III-IV (53\%) comparing to those with early stages I-II $(20 \%)(P=0.001)$ (Fig. 3D). The CDO1 promoter methylation frequency tended to be higher in HCC patients who were AFP-negative $(52.7 \%)$ comparing to those who were AFP-positive $(36.7 \%)(P=0.094)$. The level of 20 $\mathrm{ng} / \mathrm{ml}$ was used as a cut-off value to define AFP-positive.
No significant correlation was observed with other parameters, including $\mathrm{HBeAg}$ status, histological differentiation and LC ( $P=0.331, P=0.143, P=0.287$, respectively).

Furthermore, the correlation of the $C D O 1$ promoter methylation with the characteristics of HBV-related HCC was analyzed in details (Table 2). The serum CDO1 promoter methylation was more frequent in HCC patients with tumors size $>5 \mathrm{~cm}(O R=3.834, P=0.001)$, multinodular tumors $(O R=3.183, P=0.004)$ and portal or hepatic vein invasion $(O R=4.04, P<0.0001)$. 
Diagnostic value of AFP and CDO1 promoter methylation status in discriminating $\mathrm{HBV}$-related $\mathrm{HCC}$ from $\mathrm{LC}$, and CHB

The serum $C D O 1$ promoter methylation status showed the sensitivity of $42.3 \%$ and the specificity of $85.7 \%$ in discriminating HCC from LC [Youden $(\mathrm{Y})$ index $=28$ ], and $42.3 \%$ and $89.5 \%$, respectively, in discriminating $\mathrm{HCC}$ from CHB and LC (Y index = 31.8) (Table 3). The level of $20 \mathrm{ng} / \mathrm{ml}$ was used as a cut-off value to define AFPpositivity. With AFP positivity alone, the sensitivity and specificity in HCC vs. LC were $64.2 \%$ and $67.9 \%$ (Y index $=32.1)$, and $64.2 \%$ and $84.2 \%(\mathrm{Y}$ index $=48.4)$ in HCC $v s$. $\mathrm{CHB}+\mathrm{LC}$. When we combined CDO1 promoter methylation with AFP-positivity, the sensitivity and the specificity were $82.9 \%$ and $57.1 \%$ (Y index $=40)$ in HCC vs. LC and $82.9 \%$ and $75.4 \%$ ( $\mathrm{Y}$ index $=58.3$ ), respectively, in $\mathrm{HCC}$ vs. CHB + LC (Fig. 5, Table 3).

We also tested the diagnostic values of the different cut-off values for AFP including $200 \mathrm{ng} / \mathrm{ml}$ and $400 \mathrm{ng} / \mathrm{ml}$. The sensitivity and the Y index of the combined AFP positivity and $\mathrm{CDO1}$ methylation status were higher than AFP alone in both HCC vs. LC and HCC vs. LC + CHB (Fig. 5, Table 3). With AFP positivity alone, at a cut-off value of $200 \mathrm{ng} / \mathrm{ml}$, the sensitivity and the specificity in HCC vs. LC were $32.5 \%$ and $96.4 \%$ (Y index $=28.9$ ), while at a cut-off value of $400 \mathrm{ng} / \mathrm{ml}$, they were $22.8 \%$ and $96.4 \%$ ( $\mathrm{Y}$ index $=$ $19.2)$, respectively. The sensitivity and the specificity in HCC vs. CHB + LC were $32.5 \%$ and $98.2 \%$ ( $\mathrm{Y}$ index $=$ 30.7 ), respectively, at a cut-off value of $200 \mathrm{ng} / \mathrm{ml}$, and $22.8 \%$ and $98.2 \%$ ( $\mathrm{Y}$ index $=21$ ), respectively, at a cut-off value of $400 \mathrm{ng} / \mathrm{ml}$. When we combined serum CDO1 methylation status with AFP positivity, the sensitivity and the specificity were $64.2 \%$ and $82.1 \%$ (Y index $=46.3$ ), and $57.7 \%$ and $82.1 \%(\mathrm{Y}$ index $=39.8)$, respectively, in $\mathrm{HCC}$ vs. LC; $64.2 \%$ and $87.7 \%$ ( $\mathrm{Y}$ index $=51.9$ ), or $57.7 \%$ and $87.7 \%(\mathrm{Y}$ index $=45.4)$ respectively in HCC $v s . \mathrm{CHB}+\mathrm{LC}$ (Table 3).

\section{Discussion}

In this study we demonstrated that significantly elevated frequency of $\mathrm{CDO1}$ promoter methylation was detected in serum DNA from patients with HBV-related HCC comparing to patients with CHB, LC or healthy controls. The methylation frequency was significantly higher in those at advanced stages III-IV than those at early stages I-II. While the CDO1 methylation status was predictive of the presence and severity of the HCC, combining with the presence of AFP-positive (>20 ng/ml), the diagnostic value was significantly improved in HCC. While further prospective studies are needed to confirm this finding, our study suggests that serum $C D O 1$ promoter methylation status could potentially serve as an additional biomarker for the diagnosis of HBV-related HCC and assignment of the HCC stages.

The development and progression of $\mathrm{HCC}$ is a multistep process; the sequence of "chronic hepatitis-cirrhosis-
HCC" has been well established (Bruix et al. 2005). Increasing evidence has indicated that aberrant methylation of tumor suppressor genes may play an important role in the course of this multistep hepatocarcinogenesis (Lee et al. 2003; Nishida et al. 2008; Um et al. 2011). In our study, CDO1 promoter methylation was present in CHB, LC and early stages of HCC without significant differences. However, the methylation status was significantly increased in a stepwise manner towards advanced stages of HCC. The progression of $C D O 1$ promoter methylation is consistent with the sequence of "chronic hepatitis-cirrhosisHCC", suggesting that the CDOI promoter methylation may be gradually developed and contributes to the progression and metastasis of HCC. Our data were also echoed with previous study that $C D O 1$ promoter methylation was associated with adverse clinical features and poor prognosis in breast cancer (Jeschke et al. 2013). However, our study alone is not sufficient to confirm $C D O 1$ promoter methylation is associated with the progression of HBV-related HCC. In the present work, we mainly focused on the detection of the existence of $\mathrm{CDOl}$ promoter methylation in HBV-related HCC patients. We explored the correlations between the biological characteristics and the $C D O 1$ promoter methylation status, and found $C D O 1$ promoter methylation was associated with tumors size, multi-nodular tumors and portal or hepatic vein invasion. Involving the prognosis of the patients following different types of treatment and comparing the $C D O 1$ promoter methylation status with other accepted predicting scores such as Barcelona Clinical Liver Cancer (BCLC) stage (Bruix et al. 2004) and Child-Turcotte-Pugh (CTP) score (Pugh et al. 1973) will help confirm the relationship between the $C D O 1$ promoter methylation and the prognosis of HCC.

It was reported that aberrant methylation observed in human cancer could be the result of the normal aging process (Issa et al. 1994; Nishida et al. 2008). But according to our result, the methylation frequency of $C D O 1$ promoter was just slightly higher in young patients than the elderly with HCC, and this has no statistical significance. Our result found females had a slightly elevated methylation frequency than males. In agreement with our observation, previous research reported that a high frequency of $C D O 1$ down-regulation $(>80 \%)$ in female cancer patients than in male patients $(<40 \%)$ (Brait et al. 2012). It is not clear why women are more vulnerable to the $C D O 1$ epigenetic silencing than men. Further investigations will be of value in understanding the potential gender specific differences in the occurrence of HCC.

Currently, AFP is a widely used biomarker for screening $\mathrm{HCC}$, with a sensitivity of $22 \%$ to $60 \%$ and specificity of $65 \%$ to $94 \%$ depending on different cut-off values (Bruix et al. 2005; Lok et al. 2010). Combination with ultrasonography, the sensitivity may be increased. However, there are still just about $30-40 \%$ of HCC being suitable for potentially curative treatments at the time of diagnosis, possibly due to the fact that image abnormality is typically detect- 
able at late stages of the disease (Shen et al. 2012). Therefore, more sensitive and specific biomarkers are needed for the diagnosis of HCC. By alone, serum CDO1 promoter methylation status is inferior to AFP positivity in both sensitivity and specificity, but it can serve as an additional index for the diagnosis of HCC. Nowadays, the cutoff AFP level of $20 \mathrm{ng} / \mathrm{ml}$ is widely used as a screening test for HCC (Bruix et al. 2005), it means in our cohort up to $35 \%$ of our HCC cases have negative AFP levels. Combination of serum $\mathrm{CDO1}$ promoter methylation status and AFP positivity ( $>20 \mathrm{ng} / \mathrm{ml}$ ) increased the sensitivity from $64.2 \%$ to $82.9 \%$ in predicting $\mathrm{HCC}$, even though the specificity decreased from $67.9 \%$ to $57.1 \%$ in discrimination HCC from liver cirrhosis. International guidelines use AFP level of $400 \mathrm{ng} / \mathrm{ml}$ as a criterion for the diagnosis of HCC (Bruix et al. 2001), while others have reduced this cut-off level to $200 \mathrm{ng} / \mathrm{ml}$ (Bruix et al. 2005), considering its low sensitivity. Compared with AFP alone, the combined marker increased the sensitivity at the cut-off levels of both $400 \mathrm{ng} / \mathrm{ml}$ and $200 \mathrm{ng} / \mathrm{ml}$. Therefore, serum CDO1 promoter methylation may improve the potential value of AFP in the diagnosis of HBV-related HCC. To validate the diagnostic value, a large number of patients and another cohort under the guideline of The Standards for Reporting of Diagnostic Accuracy (STARD) steering committee (Bossuyt et al. 2003) are needed.

The current study has limitations with the small number of patients from a single site and its cross-sectional design. The diagnosis value of the serum $C D O 1$ promoter methylation status for HCC patients will have to be confirmed and validated by a longitudinal study, preferably by a multi-center study with a larger population.

In conclusion, methylation status of $C D O 1$ gene promoter as measured from serum samples may help diagnose HBV-related HCC and estimate the stage of HCC. Further prospective studies will be required to validate the clinical value.

\section{Acknowledgements}

This work was supported by grants from Key Project of Chinese Ministry of Science and Technology (2012ZX10002007, 2013ZX10002001), and National Natural Science Foundation of China (81171579, 81201287).

\section{Conflict of Interest}

The authors declare no conflict of interest.

\section{References}

Andresen, K., Boberg, K.M., Vedeld, H.M., Honne, H., Hektoen, M., Wadsworth, C.A., Clausen, O.P., Karlsen, T.H., Foss, A., Mathisen, O., Schrumpf, E., Lothe, R.A. \& Lind, G.E. (2012) Novel target genes and a valid biomarker panel identified for cholangiocarcinoma. Epigenetics, 7, 1249-1257.

Bossuyt, P.M., Reitsma, J.B., Bruns, D.E., Gatsonis, C.A., Glasziou, P.P., Irwig, L.M., Lijmer, J.G., Moher, D., Rennie, D. $\&$ de Vet, H.C.; Standards for Reporting of Diagnostic, Accuracy (2003) Towards complete and accurate reporting of studies of diagnostic accuracy: the STARD initiative. Stan- dards for Reporting of Diagnostic Accuracy. Clin. Chem., 49, 1-6.

Brait, M., Ling, S., Nagpal, J.K., Chang, X., Park, H.L., Lee, J., Okamura, J., Yamashita, K., Sidransky, D. \& Kim, M.S. (2012) Cysteine dioxygenase 1 is a tumor suppressor gene silenced by promoter methylation in multiple human cancers. PLoS One, 7, e44951.

Bruix, J., Boix, L., Sala, M. \& Llovet, J.M. (2004) Focus on hepatocellular carcinoma. Cancer Cell, 5, 215-219.

Bruix, J., Sherman, M., Llovet, J.M., Beaugrand, M., Lencioni, R., Burroughs, A.K., Christensen, E., Pagliaro, L., Colombo, M. \& Rodes, J.; EASL Panel of Experts on HCC (2001) Clinical management of hepatocellular carcinoma. Conclusions of the Barcelona-2000 EASL conference. European Association for the Study of the Liver. J. Hepatol., 35, 421-430.

Bruix, J. \& Sherman, M.; Practice Guidelines Committee; American Association for the Study of Liver Diseases (2005) Management of hepatocellular carcinoma. Hepatology, 42, 1208-1236.

Dietrich, D., Krispin, M., Dietrich, J., Fassbender, A., Lewin, J., Harbeck, N., Schmitt, M., Eppenberger-Castori, S., Vuaroqueaux, V., Spyratos, F., Foekens, J.A., Lesche, R. \& Martens, J.W. (2010) CDO1 promoter methylation is a biomarker for outcome prediction of anthracycline treated, estrogen receptor-positive, lymph node-positive breast cancer patients. BMC Cancer, 10, 247.

Edmondson, H.A. \& Steiner, P.E. (1954) Primary carcinoma of the liver: a study of 100 cases among 48,900 necropsies. Cancer, 7, 462-503.

Fraga, M.F. \& Esteller, M. (2002) DNA methylation: a profile of methods and applications. Biotechniques, 33, 632, 634, 636-649.

Fukushige, S. \& Horii, A. (2013) DNA methylation in cancer: a gene silencing mechanism and the clinical potential of its biomarkers. Tohoku J. Exp. Med., 229, 173-185.

Guan, Z., Zhang, J., Song, S. \& Dai, D. (2013) Promoter methylation and expression of TIMP3 gene in gastric cancer. Diagn. Pathol., 8, 110.

Issa, J.P., Ottaviano, Y.L., Celano, P., Hamilton, S.R., Davidson, N.E. \& Baylin, S.B. (1994) Methylation of the oestrogen receptor $\mathrm{CpG}$ island links ageing and neoplasia in human colon. Nat. Genet., 7, 536-540.

Jahr, S., Hentze, H., Englisch, S., Hardt, D., Fackelmayer, F.O., Hesch, R.D. \& Knippers, R. (2001) DNA fragments in the blood plasma of cancer patients: quantitations and evidence for their origin from apoptotic and necrotic cells. Cancer Res., 61, 1659-1665.

Jeschke, J., O'Hagan, H.M., Zhang, W., Vatapalli, R., Calmon, M.F., Danilova, L., Nelkenbrecher, C., Van Neste, L., Bijsmans, I.T., Van Engeland, M., Gabrielson, E., Schuebel, K.E., Winterpacht, A., Baylin, S.B., Herman, J.G. \& Ahuja, N. (2013) Frequent inactivation of cysteine dioxygenase type 1 contributes to survival of breast cancer cells and resistance to anthracyclines. Clin. Cancer Res., 19, 3201-3211.

Jung, K., Fleischhacker, M. \& Rabien, A. (2010) Cell-free DNA in the blood as a solid tumor biomarker: a critical appraisal of the literature. Clin. Chim. Acta, 411, 1611-1624.

Kwon, Y.J., Lee, S.J., Koh, J.S., Kim, S.H., Lee, H.W., Kang, M.C., Bae, J.B., Kim, Y.J. \& Park, J.H. (2012) Genome-wide analysis of DNA methylation and the gene expression change in lung cancer. J. Thorac. Oncol., 7, 20-33.

Lee, S., Lee, H.J., Kim, J.H., Lee, H.S., Jang, J.J. \& Kang, G.H. (2003) Aberrant $\mathrm{CpG}$ island hypermethylation along multistep hepatocarcinogenesis. Am. J. Pathol., 163, 1371-1378.

Lok, A.S., Sterling, R.K., Everhart, J.E., Wright, E.C., Hoefs, J.C., Di Bisceglie, A.M., Morgan, T.R., Kim, H.Y., Lee, W.M., Bonkovsky, H.L. \& Dienstag, J.L.; HALT-C Trial Group (2010) Des-gamma-carboxy prothrombin and alpha-fetoprotein as biomarkers for the early detection of hepatocellular 
carcinoma. Gastroenterology, 138, 493-502.

Nishida, N., Arizumi, T., Takita, M., Nagai, T., Kitai, S., Yada, N., Hagiwara, S., Inoue, T., Minami, Y., Ueshima, K., Sakurai, T., Ida, H. \& Kudo, M. (2013) Quantification of tumor DNA in serum and vascular invasion of human hepatocellular carcinoma. Oncology, 84 Suppl 1, 82-87.

Nishida, N., Nagasaka, T., Nishimura, T., Ikai, I., Boland, C.R. \& Goel, A. (2008) Aberrant methylation of multiple tumor suppressor genes in aging liver, chronic hepatitis, and hepatocellular carcinoma. Hepatology, 47, 908-918.

Pugh, R.N., Murray-Lyon, I.M., Dawson, J.L., Pietroni, M.C. \& Williams, R. (1973) Transection of the oesophagus for bleeding oesophageal varices. Br. J. Surg., 60, 646-649.

Robertson, K.D. (2005) DNA methylation and human disease. Nat. Rev. Genet., 6, 597-610.

Satsu, H., Terasawa, E., Hosokawa, Y. \& Shimizu, M. (2003) Functional characterization and regulation of the taurine transporter and cysteine dioxygenase in human hepatoblastoma HepG2 cells. Biochem. J., 375, 441-447.

Shen, Q., Fan, J., Yang, X.R., Tan, Y., Zhao, W., Xu, Y., Wang, N., Niu, Y., Wu, Z., Zhou, J., Qiu, S.J., Shi, Y.H., Yu, B., Tang, N., Chu, W., et al. (2012) Serum DKK1 as a protein biomarker for the diagnosis of hepatocellular carcinoma: a large-scale, multicentre study. Lancet Oncol., 13, 817-826.

Shivapurkar, N. \& Gazdar, A.F. (2010) DNA methylation based biomarkers in non-invasive cancer screening. Curr. Mol. Med., 10, 123-132.

Tischoff, I., Hengge, U.R., Vieth, M., Ell, C., Stolte, M., Weber, A., Schmidt, W.E. \& Tannapfel, A. (2007) Methylation of SOCS-3 and SOCS-1 in the carcinogenesis of Barrett's adeno- carcinoma. Gut, 56, 1047-1053.

Tsuboyama-Kasaoka, N., Hosokawa, Y., Kodama, H., Matsumoto, A., Oka, J. \& Totani, M. (1999) Human cysteine dioxygenase gene: structural organization, tissue-specific expression and downregulation by phorbol 12-myristate 13-acetate. Biosci. Biotechnol. Biochem., 63, 1017-1024.

Um, T.H., Kim, H., Oh, B.K., Kim, M.S., Kim, K.S., Jung, G. \& Park, Y.N. (2011) Aberrant CpG island hypermethylation in dysplastic nodules and early HCC of hepatitis B virus-related human multistep hepatocarcinogenesis. J. Hepatol., 54, 939-947.

Venook, A.P., Papandreou, C., Furuse, J. \& de Guevara, L.L. (2010) The incidence and epidemiology of hepatocellular carcinoma: a global and regional perspective. Oncologist, 15 Suppl 4, 5-13.

Wang, J., Qin, Y., Li, B., Sun, Z. \& Yang, B. (2006) Detection of aberrant promoter methylation of GSTP1 in the tumor and serum of Chinese human primary hepatocellular carcinoma patients. Clin. Biochem., 39, 344-348.

Zhang, Y.J., Wu, H.C., Shen, J., Ahsan, H., Tsai, W.Y., Yang, H.I., Wang, L.Y., Chen, S.Y., Chen, C.J. \& Santella, R.M. (2007) Predicting hepatocellular carcinoma by detection of aberrant promoter methylation in serum DNA. Clin. Cancer Res., 13, 2378-2384.

Zheng, Y., Wang, R., Song, H.Z., Pan, B.Z., Zhang, Y.W. \& Chen, L.B. (2013) Epigenetic downregulation of RUNX3 by DNA methylation induces docetaxel chemoresistance in human lung adenocarcinoma cells by activation of the AKT pathway. Int. J. Biochem. Cell Biol., 45, 2369-2378. 